\begin{tabular}{ccc} 
FOLIA & $\begin{array}{c}\text { ENTOMOLOGICA } \\
\text { ROVARTANI HÖZLEMÉNYEK A R A }\end{array}$ \\
Volume 80 & 2019 & pp. 327-330 \\
\hline
\end{tabular}

\title{
Choerades castellanii, new to Hungary (Diptera: Asilidae)
}

\author{
Margaux Boer Aeve ${ }^{1 *}$, Zoltán Soltész ${ }^{2,3} \&$ Ward TAMSYN $^{1}$ \\ ${ }^{1}$ Nobelberg 10, 3320 Holsbeek, Belgium. \\ E-mails:margaux.boeraeve@kuleuven.be,wardtamsyn@gmail.com \\ ${ }^{2}$ MTA Centre for Ecological Research, Lendület Ecosystem Services Research Group, \\ H-2163Vácrátót, Alkotmány utca 2-4, Hungary.E-mail:soltesz.zoltan@okologia.mta.hu \\ ${ }^{3}$ Hungarian Natural History Museum, Department of Zoology, \\ H-1088 Budapest, Baross utca 13, Hungary.E-mail:soltesz.zoltan@nhmus.hu
}

\begin{abstract}
Choerades castellanii (Hradský, 1962) is recorded from Hungary for the first time. This species was previously known only from Slovakia and Germany. Two specimens were identified from the Diptera Collection of the Hungarian Natural History Museum and one specimen was caught while sitting on a pile of logs right outside the Bükk National Park. One of the museum specimens was caught close to the Croatian-Hungarian border, so the species can also be expected to be present in Croatia. With 5 figures.
\end{abstract}

Key words - robber flies, Choerades castellanii

\section{INTRODUCTION}

With 5600 species described world-wide so far, Asilidae forms one of the most diverse families within the order Diptera (after the families Tipulidae, Tachinidae and Syrphidae) (Skevington \& DANG 2002). Both larvae and adults have a predatory lifestyle, which is rather special within Diptera. While predatory larvae are known from 39 Diptera families, adult predatory lifestyle is only found in 10 families. Apart from this predatory lifestyle, they are characterised by a mystax (a row or group of bristles on the lower edge of the face) and a heavily sclerotized, tube-like proboscis containing the needle-like hypopharynx (BY BEE et al. 2004).

It is estimated that 110 species of Asilidae occur in Hungary, however only 72 species are currently known (MAJER 2001). Low sampling intensity and the destruction of the old Asilidae collection in a fire in 1956 have limited our understanding of the Hungarian Asilidae. During a two-week holiday in the eastern part of Hungary, we found Choerades castellanii (Hradský, 1962), which is the first record of this species in the country.

${ }^{*}$ Corresponding author. 
C. castellanii was first described by HRADSKÝ (1962) based on 50 specimens caught in the eastern part of the former Czechoslovak Socialist Republic (current Slovakia). Most of the specimens were caught in the Vihorlat Mountains in July and August between 1955 and 1958 (HRADSKÝ 1962). The specimens were first identified as Choerades fulva (Meigen, 1804), but after studying material from Italy sent to Hradský by O. Castellani, Hradský realised it was a new species and he named it after his friend (HR ADSKÝ 1962). In July 1997 one male specimen of C. castellanii was also caught in the Bienwald, Germany (GELLER-GRIM et al. 2003). So far, the species was known only from Slovakia and Germany (Fig. 1).

\section{CHOERADES CASTELLANII IN HUNGARY}

Material examined - Borsod-Abaúj-Zemplén county: [Sály], Lator[puszta],

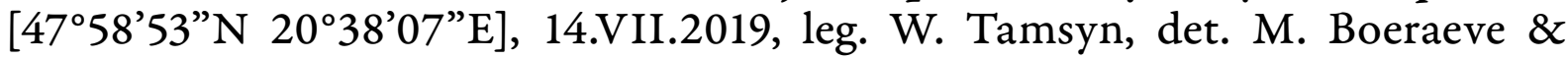

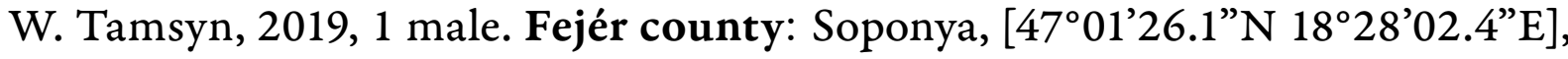
Soponyai-halastó, 21.VI.1991, leg. S. Tóth, det. Z. Soltész, 2015, 1 male. Somogy

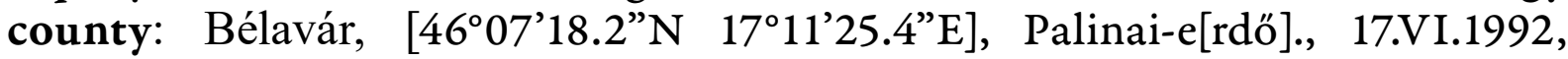
leg. S. Tóth, det. Z. Soltész, 2015, 1 male.

The voucher specimens are deposited in the Diptera Collection of the Hungarian Natural History Museum (Budapest).

Morphology - C. castellanii is a member of the Laphrinae subfamily, which is easily distinguished from other subfamilies by the lack of a long arista at the end of the antennae. The arista is largely reduced in this subfamily and can sometimes be found as a barely visible stump on the distal part of the last antennal segment.

C. castellanii is a middle-sized robberfly, with dark legs, and the ground colour of the abdomen is completely dark (Figs $2-3$ ). The fly is mostly covered in yellow-golden hairs. The thorax is dusted on the sides and on the humeri. It is most similar to the species of the C. fimbriata (Meigen, 1820) and the C. marginata (Linnaeus, 1758) species groups (Wolf f et al. 2018). These species all have a dense patch of hairs covering the face between the antennal implant and the facial knob. Like C. fimbriata it has yellow dusting and dense yellow hairs on the anepisternum and a long proboscis (a bit longer than the height of the head), while the C. marginata group has less dense yellow/white and black hairs on the anepisternum and a shorter proboscis (WoLFF et al. 2018). Males of C. castellanii are relatively easy to distinguish from $C$. fimbriata and other Choerades species by looking at the shape of the last visible tergite, which bears two protrusions on the distal side (Fig. 4). Other species lack this remarkable feature. Females are much harder to identify.

Habitat - The last specimen was caught as it was sitting on a pile of pine logs (Fig. 5) along a road in the small community of Latorpuszta (part of the village Sály) on $180 \mathrm{~m}$ a.s.l. in the southern foothills of the Bükk Mountains. In the immediate surrounding the following habitats are present: riparian forest, dry deciduous forest on limestone and flower rich grasslands on limestone. 


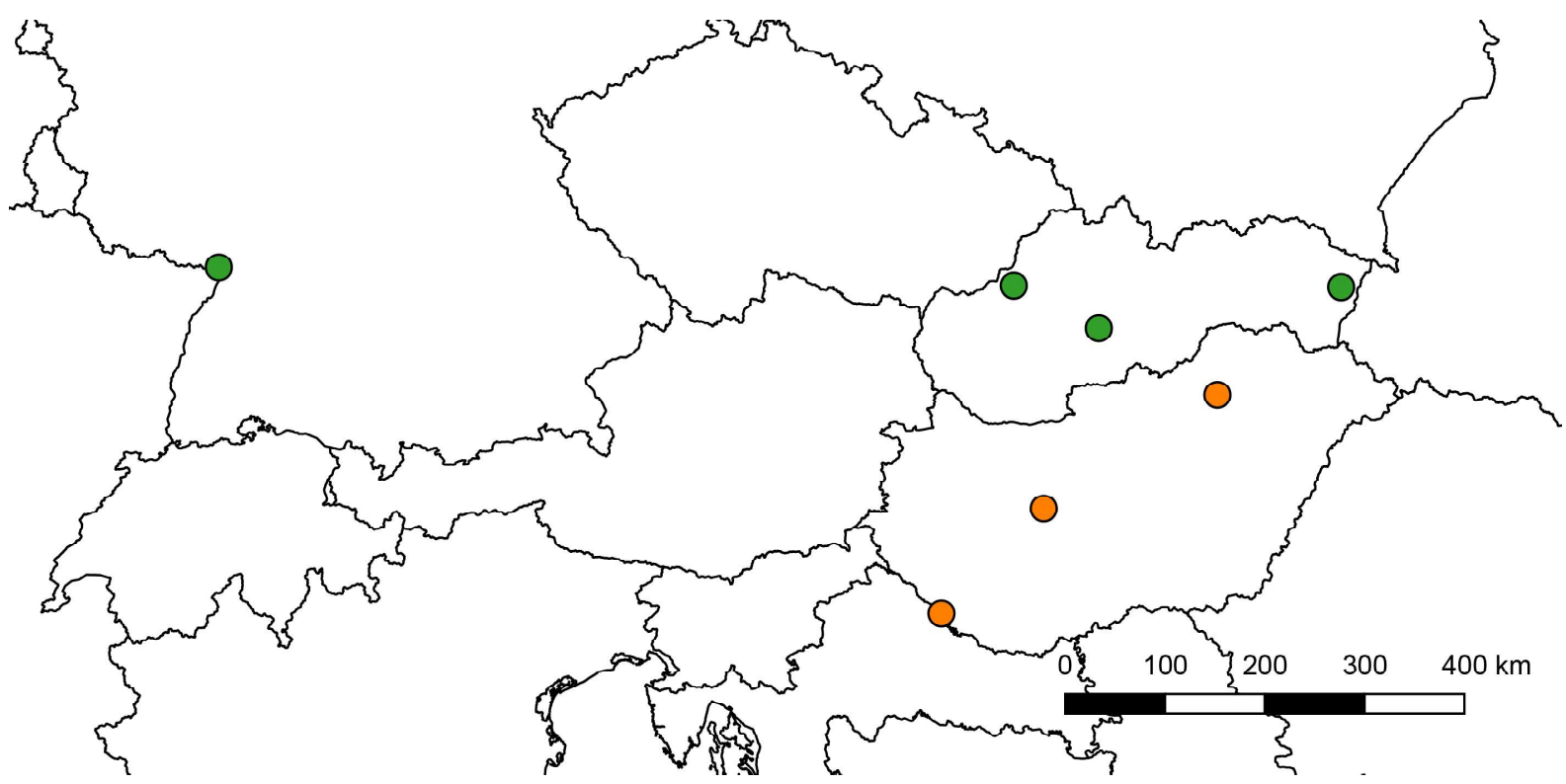

Fig 1. Localities where Choerades castellanii (Hradský, 1962) has been found before (in green) and where the species was found in Hungary (in orange). Sources: HRADSKÝ (1962) and GELLER-GRim et al. (2003)

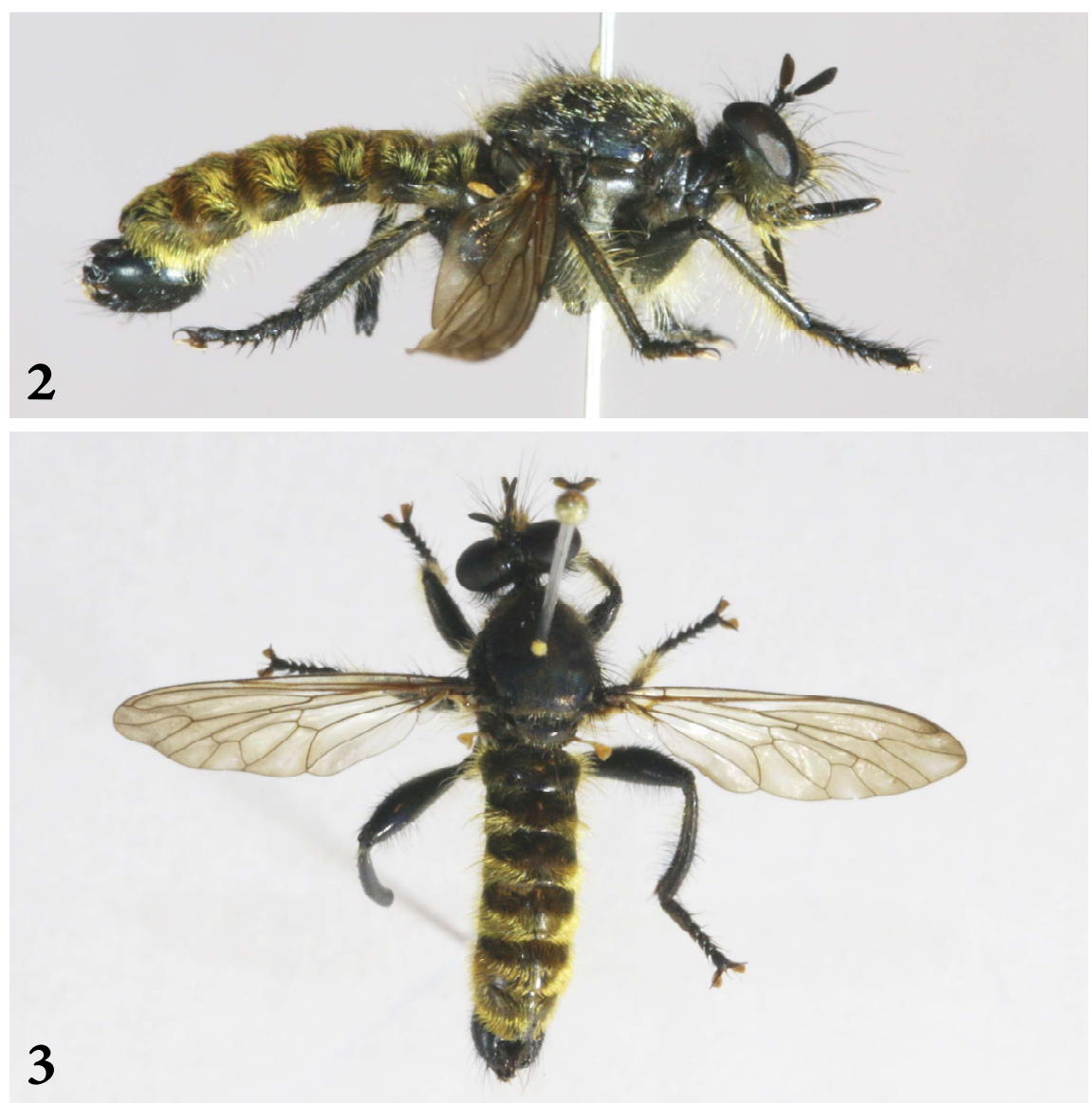

Figs 2-3. Choerades castellanii (Hradský, 1962): 2 = habitus, male, lateral view, 3 = dorsal view (photos by Margaux Boeraeve) 

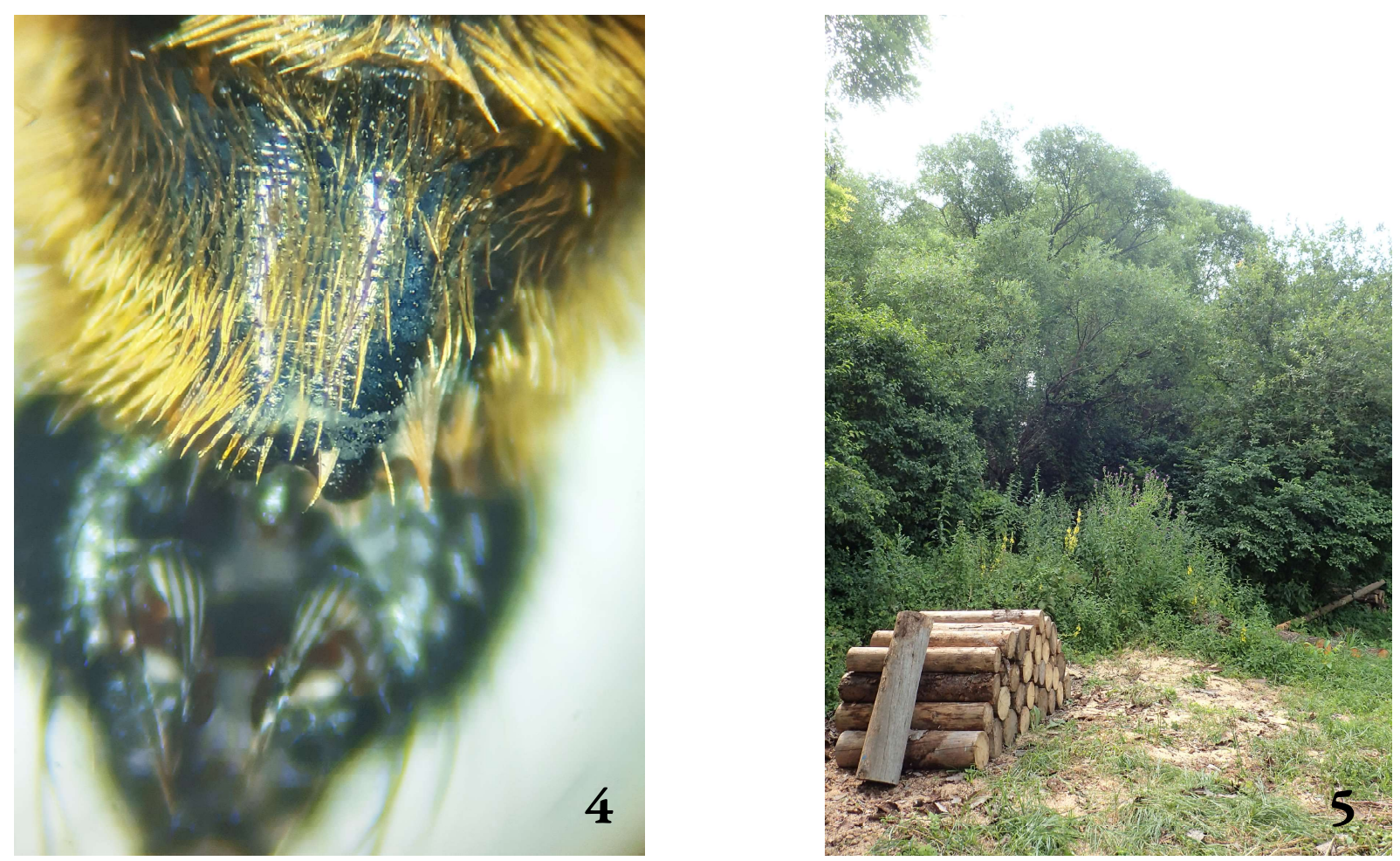

Figs 4-5. 4 = Choerades castellanii (Hradský, 1962): last visible tergite, bearing two protrusions on the distal side, 5 = Location where one of the specimens was caught (Sály, Latorpuszta, $\left.47^{\circ} 58^{\prime} 53^{\prime \prime} \mathrm{N} 20^{\circ} 38^{\prime} 07^{\prime \prime} \mathrm{E}\right)$. It was sitting on this pile of logs (photos by Margaux Boeraeve)

Acknowledgements - We would like to thank Fritz Geller-Grim (Museum Wiesbaden, Germany) for confirming the identification of our specimen.

\section{REFERENCES}

Bybee S. M., Taylor S. D., Nelson C. R. \& Whiting M. F. 2004: A phylogeny of robber flies (Diptera: Asilidae) at the subfamilial level: molecular evidence. - Molecular Phylogenetics and Evolution 30(3): 789-97. https://doi.org/10.1016/S1055-7903(03)00253-7

Geller-Grim F., Dikow T. \& Niehuis M. 2003: Raubfliegen vom Roßstein bei Dörscheid (Mittelrheintal, Rheinland-Pfalz) nebst Anmerkungen zur Verbreitung in Rheinland-Pfalz (Diptera: Asilidae). - Fauna Flora Rheinland-Pfalz 10(1): 85-98.

HradSKÝ M. 1962: Deux espèces nouvelles d'asilides de la Tchecoslovaquie, Diptera: Asilidae. Bollettino dell'Associazione Romana di Entomologia 17(1): 7-11.

Majer J. 2001: Contribution to the Asilidae Fauna of Hungary (Diptera). - Folia entomologica bungarica 62: 263-73.

Skevington J. H. \& Dang P. T. 2002: Exploring the diversity of flies (Diptera). - Biodiversity 3(4): 3-27. https://doi.org/10.1080/14888386.2002.9712613

Wolff D., Gebel M. \& Geller-Grim F. 2018: Die Raubfliegen Deutschlands. - Quelle \& Meyer Verlag GmbH, Wiebelsheim, 339 pp. 